\title{
ATHEROSCLEROSIS OF THE ASCENDING AORTA IS A PREDICTOR OF RENAL DYSFUNCTION AFTER CARDIAC OPERATIONS
}

Víctor G. Dávila-Román, MD

Nicholas T. Kouchoukos, MD

Kenneth B. Schechtman, PhD

Benico Barzilai, MD
Objectives: Renal dysfunction occurring after cardiac operations has been attributed to various factors, but the importance of an atherosclerotic thoracic aorta has not been previously evaluated. The purpose of this study was to identify predictors of postoperative renal dysfunction (50\% or more increase from preoperative values) and to evaluate the importance of atherosclerosis of the ascending aorta as a predictor of this complication. Methods: Nine hundred seventy-eight consecutive patients, 50 years of age and older with normal preoperative renal function (serum creatinine level of $1.5 \mathrm{mg} / \mathrm{dL}$ or less), who were scheduled to undergo cardiac surgery were prospectively evaluated. Atherosclerosis of the ascending aorta was assessed during the operation (with epiaortic ultrasound), and patients were divided into 3 groups according to its severity (normal-to-mild, moderate, and severe). Results: Univariate predictors of renal dysfunction at postoperative day 1 were atherosclerosis of the ascending aorta $(P<.045)$ and postoperative low cardiac output $(P=.05)$; at postoperative day 6 they were atherosclerosis of the ascending aorta $(P<.0001)$, postoperative low cardiac output $(P<.0001)$, advanced age $(P=.001)$, decreased preoperative left ventricular function $(P=.01)$, and female gender $(P=.03)$. Multivariate analysis showed that atherosclerosis of the ascending aorta (odds ratio, 3.06; $P=.04$ ) was the only independent predictor of postoperative renal dysfunction at day 1 and that postoperative low cardiac output (odds ratio, $4.83 ; P<.0001$ ), atherosclerosis of the ascending aorta (odds ratio, $2.13 ; P=.0006)$, and preoperative left ventricular dysfunction (odds ratio, $1.48 ; P=.028$ ) were independent predictors of postoperative renal dysfunction at day 6 . Conclusions: An atherosclerotic ascending aorta is an important predictor of postoperative renal dysfunction, possibly because atheroembolism to the kidneys occurs in the perioperative period (ie, during surgical manipulation of an atherosclerotic aorta) or because the diseased aorta may be a marker of widespread atherosclerotic disease that may predispose to perioperative renal dysfunction. (J Thorac Cardiovasc Surg 1999;117:111-6)
From the Cardiovascular Division, Department of Internal Medicine (V.G.D.R., B.B.); Department of Biostatistics (K.B.S.); and the Department of Surgery, Cardiothoracic Surgery Division (N.T.K.), Washington University School of Medicine and Barnes-Jewish Hospital, St Louis, Mo.

Supported in part by a Minority Investigator Research Grant (MIRS) to Dr Dávila-Román from the American Heart Association, Dallas, Texas.

Received for publication Feb 20, 1998; revisions requested May 13, 1998; revisions received July 1, 1998; accepted for publication Aug 20, 1998.

Address for reprints: Víctor G. Dávila-Román, MD, Cardiovascular Division, Box 8086, Washington University School of Medicine, 660 S Euclid Ave, St Louis, MO 63110.

Copyright (C) 1999 by Mosby, Inc.

$0022-5223 / 99 \$ 8.00+0 \quad \mathbf{1 2} / \mathbf{1} / \mathbf{9 3 9 5 1}$ ardiac and aortic operations are associated with a $\mathcal{U}$ relatively high risk of acute renal failure, with an incidence of this complication of approximately $2 \%$ to $15 \%$ and a mortality rate as high as $40 \%$ for those who experience acute renal failure. ${ }^{1-4}$ Factors associated with postoperative renal failure include advanced age, preoperative left ventricular dysfunction, active bacterial endocarditis, preexisting renal insufficiency, operations other than isolated coronary artery bypass grafting (CABG) surgery, prolonged aortic crossclamp and/or cardiopulmonary bypass (CPB) time, and low cardiac output in the perioperative period. ${ }^{5-8}$

An association between atherosclerotic disease of the 
Table I. Patient characteristics by severity of ascending aorta atherosclerosis

\begin{tabular}{|c|c|c|c|c|}
\hline Variable & $\begin{array}{l}\text { Normal to mild } \\
\qquad(n=813)\end{array}$ & $\begin{array}{l}\text { Moderate } \\
(n=124)\end{array}$ & $\begin{array}{l}\text { Severe } \\
(n=41)\end{array}$ & $\mathrm{P}$ value \\
\hline Gender, male (\%) & 61 & 59 & 56 & .7 \\
\hline Age (y) & $67 \pm 9$ & $71 \pm 8$ & $71 \pm 9$ & $<.001$ \\
\hline Preop creatinine (mg/dL) & $1.17 \pm 0.20$ & $1.18 \pm 0.21$ & $1.15 \pm 0.19$ & 6 \\
\hline $\begin{array}{l}\text { Postop creatinine, day } 1 \\
\quad(\mathrm{mg} / \mathrm{dL})\end{array}$ & $1.00 \pm 0.79$ & $1.14 \pm 0.79$ & $1.1 \pm 0.42$ & .10 \\
\hline $\begin{array}{l}\text { Postop creatinine, day } 6 \\
(\mathrm{mg} / \mathrm{dL})\end{array}$ & $1.14 \pm 0.79$ & $1.22 \pm 0.45$ & $1.37 \pm 0.91$ & .006 \\
\hline Postop low cardiac output (\%) & 10 & 16 & 22 & .008 \\
\hline Preop LV function* & $9.0 \pm 3.8$ & $8.9 \pm 3.7$ & $9.2 \pm 4.5$ & .9 \\
\hline CPB time (min) & $117 \pm 41$ & $125 \pm 39$ & $138 \pm 46$ & .001 \\
\hline Aortic crossclamp time (min) & $73 \pm 29$ & $77 \pm 31$ & $95 \pm 36$ & $<.0001$ \\
\hline
\end{tabular}

Values are given $\pm \mathrm{SD}$. $L V$, Left ventricular; $C P B$, cardiopulmonary bypass.

*Left ventricular wall motion score.

thoracic aorta and thrombotic and/or cholesterol embolism to the brain or peripheral organs has long been established, ${ }^{9-19}$ but until recently, atheroembolism has been considered an infrequent postoperative complication in patients undergoing cardiac surgery. We and others have shown that an atherosclerotic ascending aorta is an independent predictor of postoperative stroke in patients undergoing cardiac operations. ${ }^{20-24}$ However, the importance of an atherosclerotic aorta as a predictor of postoperative renal dysfunction has not been previously evaluated.

The primary end point of this study was to identify predictors of postoperative renal dysfunction after cardiac operations. The severity of ascending aorta atherosclerosis (by epiaortic ultrasound) at the time of the operation was compared with preoperative and postoperative serum creatinine levels at days 1 and 6 afterward. Our hypothesis was that increasing severity of atherosclerosis of the ascending aorta would be significantly and independently associated with postoperative renal dysfunction.

\section{Methods}

Patient population. A total of 978 consecutive patients, 50 years old or older (mean, 68 years; range, 50-90 years), with normal renal function (serum creatinine $\leq 1.5 \mathrm{mg} / \mathrm{dL}$ ) who were scheduled to undergo a heart operation were prospectively evaluated. There were 593 men and 385 women who underwent the following operative procedures: CABG, 685 patients (70\%); CABG and valve surgery, 176 patients (18\%); isolated valve surgery, 49 patients $(5 \%)$; valve surgery and other procedures, 59 patients $(6 \%)$; and miscellaneous cardiac surgical procedures, 9 patients (1\%). Postoperative renal dysfunction was defined as an increase from baseline preoperative levels of $50 \%$ or more in the serum creatinine at postoperative days 1 and 6. Patients with preoperative renal dys- function (serum creatinine level $>1.5 \mathrm{mg} / \mathrm{dL}$ ) were excluded from the study because they comprised a small and heterogenous group. This research was approved by the Institutional Review Board at Washington University, and each patient enrolled gave informed consent for participation.

Definition of variables analyzed. Demographic and historical data were recorded as previously described $20,23,24$ and included age, sex, history of hypertension necessitating treatment with antihypertensive medication, history of diabetes mellitus (insulin or oral hypoglycemic therapy or a carbohydrate-restricted diet), history of smoking (yes/no), history of peripheral vascular disease, and use of aspirin and/or warfarin at the time of admission. Left ventricular function was assessed angiographically in the right anterior oblique projection according to Coronary Artery Surgery Study criteria $^{25}$ : a left ventricular score of 5 was normal, a score of 6 to 10 was mild left ventricular dysfunction, 11 to 15 was moderate dysfunction, and more than 16 was severe dysfunction. Another option was to evaluate left ventricular function on the basis of left ventricular ejection fraction measured by echocardiography. Left ventricular ejection fraction of more than $55 \%$ (score of 5 ) was normal, $40 \%$ to $54 \%$ (score of 8 ) was mild dysfunction, $25 \%$ to $39 \%$ (score of 12 ) was moderate dysfunction, and less than $24 \%$ (score of 16) was severe dysfunction. Extent of coronary artery disease was evaluated as the number of major epicardial vessels with more than $50 \%$ obstruction or more. Carotid duplex scanning was performed in all patients who were 65 years old or older and in younger patients with carotid bruits or a history of transient ischemic attack or stroke. Results of the carotid ultrasound study were considered indicative of severe disease if a percent diameter reduction of 75 or more was present in one or both internal carotid arteries. The presence of anterior myocardial infarction was evaluated by 12-lead electrocardiography ( $Q$ waves in $\left.V_{1}-V_{3}\right)$. Serum cholesterol level was assessed as a continuous variable. Postoperative low output state was defined as a cardiac index of less than $2 \mathrm{~L} / \mathrm{min}$ per square meter that persisted for a period greater than 24 hours 
Table II. Univariate predictors of postoperative renal dysfunction

\begin{tabular}{|c|c|c|c|}
\hline Variable & $\begin{array}{c}\text { No renal } \\
\text { dysfunction }\end{array}$ & $\begin{array}{c}\text { Renal } \\
\text { dysfunction }\end{array}$ & $\begin{array}{c}\mathrm{P} \\
\text { value }\end{array}$ \\
\hline \multicolumn{4}{|l|}{ Change from preop to postop day 1} \\
\hline \multicolumn{4}{|l|}{ Gender } \\
\hline Male, n (\%) & $583(98.3)$ & $10(1.7)$ & .6 \\
\hline Female, n (\%) & $380(98.7)$ & $5(1.3)$ & \\
\hline Age (y) & $68 \pm 9$ & $68 \pm 10$ & .9 \\
\hline Aortic crossclamp time (min) & $74 \pm 30$ & $91 \pm 50$ & .4 \\
\hline CPB time (min) & $118 \pm 41$ & $130 \pm 52$ & .3 \\
\hline Preop LV function* & $9 \pm 4$ & $10 \pm 4$ & .7 \\
\hline \multicolumn{4}{|l|}{ Postop cardiac output } \\
\hline $\mathrm{CI} \geq 2 \mathrm{~L} / \mathrm{min} / \mathrm{m}^{2}, \mathrm{n}(\%)$ & $859(98.7)$ & $11(1.3)$ & .05 \\
\hline $\mathrm{CI}<2 \mathrm{~L} / \mathrm{min} / \mathrm{m}^{2}, \mathrm{n}(\%)$ & $104(96.4)$ & $4(3.6)$ & \\
\hline \multicolumn{4}{|l|}{ Ascending aorta atherosclerosis } \\
\hline Normal to mild, n (\%) & 804 (98.9) & $9(1.1)$ & .04 \\
\hline Moderate, n (\%) & $119(96.0)$ & $5(4.0)$ & \\
\hline Severe, n (\%) & $40(97.6)$ & $1(2.4)$ & \\
\hline \multicolumn{4}{|c|}{ Change from preop to postop day 6} \\
\hline \multicolumn{4}{|l|}{ Gender } \\
\hline Male, n (\%) & $567(95.9)$ & $24(4.1)$ & .03 \\
\hline Female, n (\%) & $349(92.8)$ & $27(7.2)$ & \\
\hline Age (y) & $67 \pm 9$ & $71 \pm 7$ & .001 \\
\hline Aortic crossclamp time (min) & $74 \pm 29$ & $77 \pm 34$ & .5 \\
\hline CPB time (min) & $117 \pm 39$ & $124 \pm 48$ & .2 \\
\hline Preop LV function* & $9 \pm 4$ & $10 \pm 4$ & .01 \\
\hline \multicolumn{4}{|l|}{ Postop cardiac output } \\
\hline $\mathrm{CI} \geq 2 \mathrm{~L} / \mathrm{min} / \mathrm{m}^{2}, \mathrm{n}(\%)$ & $835(96.3)$ & $32(3.7)$ & $<.0001$ \\
\hline $\mathrm{CI}<2 \mathrm{~L} / \mathrm{min} / \mathrm{m}^{2}, \mathrm{n}(\%)$ & $81(81.5)$ & $19(18.5)$ & \\
\hline \multicolumn{4}{|l|}{ Ascending aorta atherosclerosis } \\
\hline Normal to mild, $\mathrm{n}(\%)$ & $771(95.9)$ & $33(4.1)$ & $<.0001$ \\
\hline Moderate, n (\%) & $111(91.0)$ & $11(9.0)$ & \\
\hline Severe, $\mathrm{n}(\%)$ & $34(82.9)$ & $7(17.1)$ & $<.0001$ \\
\hline
\end{tabular}

Values are given $\pm \mathrm{SD}$. $C P B$, Cardiopulmonary bypass; $L V$, left ventricular; $C I$, cardiac index.

*Left ventricular wall motion score.

despite the use of inotropic drugs and/or intra-aortic balloon counterpulsation. All data were collected prospectively by one of the investigators who was blinded to the results of the epiaortic ultrasound findings.

Ultrasonic methods and analysis. Epiaortic ultrasound of the ascending aorta was performed intraoperatively before the institution of cardiopulmonary bypass, as previously described. ${ }^{20,23,24}$ In brief, after induction of anesthesia, the chest was opened, and the heart was suspended in a pericardial cradle filled with sterile saline solution. A 7.0-MHz linear ultrasound transducer was inserted in a sterile sheath and placed directly over the ascending aorta. Transverse and longitudinal images of the ascending aorta were obtained from the aortic root to the proximal aortic arch; these were analyzed by an observer blinded to the clinical data. The images were evaluated for the presence of atherosclerosis, which was classified according to its severity as follows: (1) normal-tomild, (2) moderate, and (3) severe. Normal-to-mild atherosclerosis was defined as less than 3-mm intimal thickening
Table III. Independent predictors of postoperative renal dysfunction

\begin{tabular}{lccc}
\hline & OR & CI (95\%) & P value \\
\hline Preop to postop day 1 & & & \\
$\quad$ Ascending aorta atherosclerosis & 3.06 & $1.06-8.85$ & .04 \\
$\quad$ Low postop cardiac output & 2.25 & $0.79-8.40$ & .1 \\
Preop to postop day 6 & & & \\
$\quad$ Low postop cardiac output & 4.83 & $2.54-9.17$ & $<.0001$ \\
Ascending aorta atherosclerosis & 2.13 & $1.40-3.26$ & .0006 \\
Preop LV function & 1.48 & $1.04-2.11$ & .03 \\
\hline
\end{tabular}

$O R$, Odds ratio; $C I$, confidence intervals; $L V$, left ventricular.

without intimal irregularities; moderate consisted of 3-5 mm or more intimal thickening; severe atherosclerosis as $5 \mathrm{~mm}$ or more intimal thickening and/or diffuse irregularities, large protruding atheromatous debris or thrombi, extensive calcification, and/or ulcerated plaques.

Statistics. Statistical analysis was performed by use of the $\chi^{2}$ test or 2-tailed Fisher's exact test when sample size was too small for $\chi^{2}$ test. The best set of independent predictors of an event was determined by stepwise logistic regression analysis of all variables. Because only 1 patient had severe atherosclerosis of the ascending aorta at postoperative day 1 , the variables moderate and severe atherosclerosis were combined in the multivariate analysis for this analysis only.

\section{Results}

Of the 978 patients with normal preoperative renal function, $15(1.5 \%)$ developed postoperative renal dysfunction (ie, a $50 \%$ or more increase in serum creatinine levels) at postoperative day 1. At postoperative day 6, serum creatinine levels were available for 967 patients; 51 patients $(5.3 \%)$ met the criteria for postoperative renal dysfunction. Patient characteristics grouped by severity of ascending aorta atherosclerosis are listed in Table I. The preoperative serum creatinine level was similar in all these groups at baseline (day 1) but was significantly higher in the patients with moderate and severe aortic atherosclerosis at postoperative day 6 .

Univariate predictors of postoperative renal dysfunction. Historic risk factors known to be associated with postoperative renal insufficiency were evaluated by univariate analysis (Table II). More women than men developed postoperative renal dysfunction at day 6. There was no difference in age between patients in whom postoperative renal dysfunction developed and those in whom it did not at day 1; at day 6, however, patients in whom postoperative renal dysfunction developed were significantly older than those in whom it did not. There was no difference in terms of aortic crossclamp time or CPB time between those in whom postoperative renal dysfunction developed and those in 
whom it did not. A higher preoperative wall motion score index, indicative of left ventricular dysfunction, was significantly associated with the development of postoperative renal dysfunction at day 6. Patients with moderate and severe atherosclerosis of the ascending aorta had a significantly higher incidence of postoperative renal dysfunction at both day $1(P=.045)$ and day $6(P<.0001)$. In addition, a postoperative low output state was also a univariate predictor of postoperative renal dysfunction on days 1 and 6 .

Multivariate predictors of postoperative renal dysfunction. A multiple logistic regression model showed that atherosclerosis of the ascending aorta $(P<$ .04) was the only independent predictor of postoperative renal dysfunction at day 1; and postoperative low cardiac output $(P<.0001)$, atherosclerosis of the ascending aorta $(P=.0006)$, and left ventricular dysfunction $(P=.028)$ were independent predictors of postoperative renal dysfunction at day 6 after the cardiac operation (Table III). There was a 5-fold increase in the risk of postoperative renal insufficiency in those with postoperative low cardiac output and a 2-fold increase in the risk of postoperative renal insufficiency in patients with significant atherosclerosis of the ascending aorta at postoperative day 6 . In those with preoperative left ventricular dysfunction, the odds ratio obtained by comparing the patients in the 75 th percentile with those in the 50th percentile showed a modest increased risk for the development of postoperative renal dysfunction.

\section{Discussion}

In this prospective study, we evaluated variables that have traditionally been associated with renal dysfunction in 978 consecutive patients with normal preoperative renal function who were undergoing a cardiac operation. We also assessed the severity of atherosclerosis of the ascending aorta and determined its relationship to postoperative renal dysfunction. We found that, in addition to traditional variables such as low postoperative cardiac output and decreased preoperative left ventricular function, atherosclerosis of the ascending aorta was an independent predictor of postoperative renal dysfunction.

Acute renal failure and/or dysfunction is defined as a significant reduction in glomerular filtration rate that occurs over a period of 2 weeks or less, ${ }^{1}$ but the definition of postoperative renal failure varies from study to study. Although some define renal failure as an increase in the serum creatinine level of $0.5 \mathrm{mg} / \mathrm{dL}$ or more, an increase of more than $50 \%$ over the baseline creatinine value, or a decrease in the calculated creatinine clear- ance of more than $50 \%$, others use definitions such as a serum creatinine level of $2.5 \mathrm{mg} / \mathrm{dL}$ or more or a decrease in renal function that results in a need for dialysis. $^{2-8,26}$ Serum creatinine levels and blood urea nitrogen are widely used tests of renal function. Because both creatinine and urea are filtered by the glomerulus, the blood levels of either can be used as indexes of glomerular filtration rate (GFR), but creatinine is a more reliable index because it is not dependent on the urine flow rate or the nitrogen balance. Because there is a predictable relationship between GFR and serum creatinine, for every $50 \%$ decrease in GFR there is a doubling of the serum creatinine concentration. ${ }^{27}$ In the present study, postoperative renal dysfunction was defined as an increase in serum creatinine level of $50 \%$ or more from preoperative values, a criterion that appears justified on the basis of the relationship between serum creatinine and GFR.

In patients who are undergoing cardiac operation, the perioperative period is characterized by a multitude of potentially adverse effects that can contribute to renal failure. Factors identified by most studies include advanced age, preoperative left ventricular dysfunction, active bacterial endocarditis, pre-existing renal insufficiency, performance of an operation other than isolated CABG, prolonged aortic crossclamp and/or CPB time, and perioperative low cardiac output. ${ }^{5-8}$ Other potentially detrimental factors include fluid shifts, hormonal alterations, hemodynamic changes, exposure to toxins such as contrast dyes, and use of medications such as antibiotics and antihypertensive drugs (ie, angiotensinconverting enzyme inhibitors). Our study identifies atherosclerosis of the ascending aorta as the only independent predictor of postoperative renal dysfunction at day 1 and a more powerful independent predictor at postoperative day 6 than any of these previously identified factors except low postoperative cardiac output.

Atheroembolism was first reported as a clinical entity in 1945 by Flory, ${ }^{13}$ who described organized cholesterol crystals in small arterioles in 9 patients with advanced aortic atherosclerosis. Histopathologic studies show that 1 to 2 days after the injection of atheromatous material, needle-shaped crystals surrounded by leukocytes are found in the lumen of small-to-medium arterioles. This is followed by an inflammatory reaction and endothelial overgrowth in 7 to 10 days. ${ }^{16}$ Atheroembolic renal disease is an increasingly recognized clinical entity that has been described to occur after aortic angiography and/or aortic operations. In their original description of autopsy results in 22 patients who died after abdominal aortic surgery, Thurlbeck and Castleman ${ }^{16}$ found evidence of athero- 
emboli in 77\%; and among 8 patients with severe embolization, 4 died from uremia 4 to 22 days after the operation. More recently, Thadhani and colleagues ${ }^{28}$ reviewed case histories of 52 patients with biopsyproven atheroembolic renal failure after invasive procedures. The decline in renal function started immediately after the procedure and peaked 3 to 8 weeks later; 23 patients underwent dialysis within 6 months of the invasive procedure. Thus atheroembolic renal disease, as depicted in the literature, appears to be a progressive process associated with high morbidity and mortality. Unfortunately, because most of the case reports emphasize the histologic aspect of the disease, the true prevalence and course of the disease is not well defined. Specifically, there are no prospective studies looking at the incidence of procedure-related atheroembolic renal dysfunction. The postulated mechanism of injury leading to atheroembolic renal failure involves multiple, repetitive atheroembolic events leading to renal dysfunction initially, but ultimately resulting in chronic renal failure. We postulate that postoperative renal dysfunction associated with a cardiac operation is also multifactorial, involving repetitive injury to the kidneys from angiography, contrast dye, left ventricular dysfunction, hypotension, and atheroembolism. However, this injury stops in most patients shortly after the cardiac operation, so that the renal dysfunction does not continue to progress.

An atherosclerotic thoracic aorta has been recognized for years as a probable contributor to neurologic events (ie, transient ischemic attacks or stroke), ${ }^{9-12}$ peripheral embolism, ${ }^{13-15}$ and renal failure. ${ }^{16-17}$ In particular, the problem of intraoperative atheroembolism during a cardiac operation has become increasingly recognized. ${ }^{20-24}$ Results from previous studies by our group have shown that atherosclerosis of the ascending aorta increases with increasing age of the patient, from $9.6 \%$ in the sixth decade to $32.6 \%$ in the ninth decade of life. Blauth and colleagues ${ }^{29}$ showed that a significant percentage of patients who died after a cardiac operation had evidence of atheroembolism, with more than $65 \%$ of them showing evidence of multiple embolic sites, the most common of which were in the brain $(16 \%)$, the spleen $(11 \%)$, the kidneys $(10 \%)$, and the pancreas $(7 \%)$. These investigators found a high correlation between atheroemboli and severe atherosclerosis of the ascending aorta. Even though a cause and effect between atherosclerosis of the aorta and postoperative renal dysfunction has not been definitively shown in the present study, the univariate analysis of data collected at day 6 (Table II) shows a statistically significant increase in the incidence of postoperative renal dysfunction as the severity of ascending aorta atherosclerosis increases from normal-mild $(4.1 \%)$ to moderate $(9.0 \%)$ to severe $(17.1 \%)$.

Although a large number of patients without significant atherosclerosis had postoperative renal dysfunction, in this patient population, a number of other factors may have been playing a role. A large number of these patients were elderly patients, and the elderly have a lower GFR that may be a contributor to renal failure. In addition they are particularly susceptible to prerenal azotemia because of their predisposition to hypovolemia and their high prevalence of atherosclerotic disease of the renal arteries. ${ }^{30}$ Therefore the precise mechanisms by which an atherosclerotic thoracic aorta predisposes to postoperative renal dysfunction remains to be defined.

\section{Conclusions}

Atherosclerosis of the ascending aorta is an independent predictor of postoperative renal dysfunction after a cardiac operation. Possible mechanisms remain speculative, but it may be that atheroembolism to the kidneys occurs in the perioperative period (ie, during surgical manipulation of an atherosclerotic aorta) or that aortic disease represents a marker for widespread atherosclerosis. The predictive value of aortic atherosclerosis with regard to the development of postoperative renal insufficiency and the value of preventive strategies remains to be defined in prospective trials.

We thank Steven B. Miller, MD, from the Nephrology Division at Washington University, for careful review of the manuscript.

\section{REFERENCES}

1. Kellerman PS. Perioperative care of the renal patient. Arch Intern Med 1994;154:1674-88.

2. Zanardo G, Michielon P, Paccagnella A, Rosi P, Caló M, Salandin $\mathrm{V}$, et al. Acute renal failure in the patient undergoing cardiac operation. J Thorac Cardiovasc Surg 1994;107:1489-95.

3. Gornick CC Jr, Kjellstrand CM. Acute renal failure complicating aortic aneurysm surgery. Nephron 1983;35:145-57.

4. Olsen PS, Schroeder T, Agerskov K, Roder O, Sorensen S, Perko M, et al. Surgery for abdominal aortic aneurysms: a survey of 656 patients. J Cardiovasc Surg 1991;32:636-42.

5. Corwin HL, Sprague SM, DeLaria GA, Norusis MJ. Acute renal failure associated with cardiac operations. J Thorac Cardiovasc Surg 1989;98:1107-12.

6. Svensson LG, Coselli JS, Sari HJ, Hess K, Crawford ES. Appraisal of adjuncts to prevent acute renal failure after surgery on the thoracic or thoracoabdominal aorta. J Vasc Surg 1989; 10:230-9.

7. Schmitt H, Riehl J, Boseila A, Kreis A, Pütz-Stork, Lo BB, et al. Acute renal failure following cardiac surgery: pre- and perioperative clinical features. Contrib Nephrol 1991;93:98-104. 
8. Novis BK, Roizen MF, Aronson S, Thisted RA. Association of preoperative risk factors with postoperative acute renal failure. Anesth Analg 1994;78:143-9.

9. Winter WJ. Atheromatous emboli: a cause of cerebral infarction. Arch Pathol 1957;64:137-42.

10. Sturgill BC, Netsky MG. Cerebral infarction by atheromatous emboli. Arch Neurol 1963;76:185-96.

11. Soloway HB, Aronson SM. Atheromatous emboli to central nervous system. Arch Pathol 1964;11:657-67.

12. Beal MF, Williams RS, Richardson EP Jr, Fisher CM. Cholesterol embolism as a cause of transient ischemic attacks and cerebral infarction. Neurology 1981;31:860-5.

13. Flory CM. Arterial occlusions produced by emboli from eroded aortic atheromatous plaques. Am J Pathol 1945;21: 549-58.

14. Hoye SJ, Teitelbaum S, Gore I, Warren R. Atheromatous embolization: a factor in peripheral gangrene. N Engl J Med 1959; 261:128-31.

15. Gore I, Collins DP. Spontaneous atheromatous embolization: review of the literature and report of 16 additional cases. Am J Clin Pathol 1960;33:416-26.

16. Thurlbeck WM, Castleman B. Atheromatous emboli to the kidneys after aortic surgery. N Engl J Med 1957;257:442-7.

17. Fraser I, Ihle B, Kincaid-Smith P. Renal failure due to cholesterol emboli. Aust N Z J Med 1991;21:418-21.

18. Amarenco P, Duyckaerts C, Tzourio C, Hénin D, Bousser MG, Hauw JJ. The prevalence of ulcerated plaques in the aortic arch in patients with stroke. N Engl J Med 1992;362:221-5.

19. The French Study of Aortic Plaques in Stroke Group. Atherosclerotic disease of the aortic arch as a risk factor for recurrent ischemic stroke. N Engl J Med 1996;334:1216-21.

20. Dávila-Román VG, Barzilai B, Wareing TH, Murphy SF, Kouchoukos NT. Intraoperative ultrasonographic evaluation of the ascending aorta in 100 consecutive patients undergoing cardiac surgery. Circulation 1991;84(suppl):III47-53.

21. Hosoda Y, Watanabe M, Hirooka Y, Ohse Y, Tanaka A, Watanabe T. Significance of atherosclerotic changes of the ascending aorta during coronary bypass surgery with intraoperative detection by echography. J Cardiovasc Surg 1991;32:301-6.

22. Ohteki H, Itoh T, Natsuaki M, Minato N, Suda H. Intraoperative ultrasonic imaging of the ascending aorta in ischemic heart disease. Ann Thorac Surg 1990;50:539-42.

23. Wareing TH, Dávila-Román VG, Barzilai B, Murphy SF, Kouchoukos NT. Management of the severely atherosclerotic ascending aorta during cardiac operations. J Thorac Cardiovasc Surg 1992;103:453-62.

24. Wareing TH, Dávila-Román VG, Daily BB, Murphy SF, Barzilai B, Kouchoukos NT. Strategy for the prevention of stroke in cardiac surgical patients. Ann Thorac Surg 1993;55:1400-7.

25. The Principal Investigators of CASS and their Associates: the National Heart, Lung, and Blood Institute coronary artery surgery study (CASS). Circulation 1981;63(suppl):I1-39.

26. Thadhani R, Pascual M, Bonventre JV. Acute renal failure. N Engl J Med 1996;334:1448-60.

27. Kassirer JP. Clinical evaluation of kidney function-glomerular function. N Engl J Med 1971;285:385-9.

28. Thadhani RI, Camargo CA, Xavier RJ, Fang LST, Bazari H. Atheroembolic renal failure after invasive procedures: natural history based on 52 histologically proven cases. Medicine 1995;74:350-8.

29. Blauth CI, Cosgrove DM, Webb BW, Ratliff NB, Boylan M, Piedmonte MR, et al. Atheroembolism from the ascending aorta: anemerging problem in cardiac surgery. $\mathrm{J}$ Thorac Cardiovasc Surg 1992;103:1104-12.

30. Pascual J, Liano F, Ormno J. The elderly patient with acute renal failure. J Am Soc Nephrol 1995;6:144-53. 